\title{
Balancing Function and Environment toward Sustainable Design: A Building Insulation Case Study
}

\author{
Celine Manoosingh ${ }^{1}$ \\ ${ }^{1}$ College of Engineering \& I.T., Georgia Southern University, Statesboro, GA, USA \\ Correspondence: Celine Manoosingh, College of Engineering \& I.T., Georgia Southern University, Statesboro, \\ GA, USA. E-mail: cmanoosingh@georgiasouthern.edu
}

\author{
Received: June 27, 2016 Accepted: July 30, 2016 Online Published: September 27, 2016 \\ doi:10.5539/jsd.v9n5p207 URL: http://dx.doi.org/10.5539/jsd.v9n5p207
}

\begin{abstract}
This study utilizes a proposed sustainable design process to investigate the functional and environmental metrics associated with an alternative insulation for use in buildings. A prototype exploring the use of evacuated packets of a silica compound substituting for conventional insulation was assessed. Assessment criteria included experimental comparison of heat transfer characteristics, as compared to a control facility. Additionally, a comprehensive environmental life cycle assessment and disassembly analysis was performed. Pilot study results indicate that in the new insulation design applied to the unit, heat flux decreased by an average of $4 \%$, and improved environmental sustainability, resulting in a savings of 1.2 metric tons of $\mathrm{CO}_{2}$ e over 20 years per 100 sq. $\mathrm{ft}$. of insulation replaced. Results provide an alternative insulation design for use in construction, and a framework by which to assess the efficiency and environmental performance of sustainable building products.
\end{abstract}

Keywords: sustainability, thermal efficiency, insulation, life cycle assessment

\section{Introduction}

\subsection{Guiding Sustainable Design}

With an increasing consumer demand for environmentally friendly building products and materials, sustainability is becoming a paramount concern to key stakeholders in the construction industry. Insulation materials used in homes and commercial buildings play a primary role in their overall energy efficiency, and the production and disposal of the voluminous amount of insulation materials poses a significant environmental challenge. As sustainability becomes a primary goal for engineers, a decision making framework is needed to guide their choice of materials and processes; and then to carry out the evaluation of their chosen design.

A review of interdisciplinary frameworks and approaches to the sustainable design process was undertaken by Little et al (2016) identified key gaps in existing sustainability assessment approaches. Among these foundational flaws is the lack of a consistent definition of "sustainability", and the inability for simple frameworks to address design at a broad and systems level that incorporates the complicated relationships including environmental, social, and economic considerations. Design-based approaches to sustainable design include green accounting, which incorporates principles of cost-benefit analysis into company accounting practices in order to provide a measure of accountability in business practices. An example of the structure of this approach was described by Dillard \& Marshall (2005) which predisposes a key paradigm shift where business accounting is tied to environmental outcomes, facilitated by a transformed social system. Design approaches for green engineering include the " 12 Principles of Green Engineering" is one such framework that seeks to achieve environmental sustainability through a set of guiding principles (Anastas \& Zimmerman, 2003). The principles of green engineering have been applied to many industries. Among them, the textile industry (Allwood, 2008), industrial parks (Lei et al, 2012), the aerospace sector (Zimmerman, 2005), as well as green chemistry and engineering (Mulvihill, et al., 2011).These twelve principles guided the development of the decision-making framework to evaluate an alternative building insulation in this work. The sustainable design process and the product developed through its application work concurrently with functionality and sustainability evaluation methodologies to cultivate a continuous loop of design, implementation, assessment and improvement. 


\subsection{Building Insulation Case Study}

This work applies the proposed decision-making framework to building insulation because of the urgent need for sustainable and cost-effective solutions to reduce the significant solid waste generated by this material reaching the end of its functional life during building deconstruction and demolition. Traditionally, the most common type of insulations utilized in buildings are mineral wool, expanded polystyrene (EPS), extruded polystyrene (XPS), cellulose, cork and polyurethane (Jelle, 2011). Mineral wool is typically utilized in frame homes and other structures where there are cavities that need to be filled. Measured thermal conductivity for this type of insulation is from $0.2-0.3 \mathrm{Wm}-1 \mathrm{~K}-1$. EPS and XPS are similar, in that they are manufactured from crude oil in combination with an expansion agent, and has thermal conductivity values that vary from $0.4-0.7 \mathrm{Wm}-1 \mathrm{~K}-1$. Cellulose and cork are typically less production-intensive, and have similar thermal conductivity values to EPS and XPS, but cost is usually a prohibitive factor in its use in building insulation. Expanded polyurethane is used commonly as an expanding foam on job sites to fill cavities between frames and to seal structures together, as it serves the dual purpose of insulation and adhesive. Great strides have been made in improving heat conductivity metrics in these traditional insulations, and in the development of new technologies such as vacuum insulation panels.

The volume of insulation material, however, as well as variances in material composition, makes efficient reuse and recycling difficult. In fact, a survey of three insulation manufacturers revealed that they used little to no reclaimed insulation materials. The deconstruction and demolition of these structures results in these insulation materials being sent to the landfill, contributing to a significant environmental challenge. It should also be noted, that when crude oil based insulation is incinerated, it emits carbon monoxide, nitrogen oxides, isocyanine, acrylonitrile, and hydrogen cyanide in levels exceeding those allowed by the EPA (EPA, 2011). In order to address the key question of a more sustainable building insulation, and find a solution to the challenge end of the life disposal for insulation, one must consider the fundamental design of the product itself. To replace outdated and inefficient design with streamlined, innovative solutions manufacturers must consider the unit from conception to the end of its life. Sustainability and life cycle thinking must become a preliminary design objectives for manufacturers as they consider building insulation alternatives.

In this context, this work investigated the redesign of the insulation of a building. The primary objective of this study was to develop an alternative insulation that improves building energy efficiency and sustainability metrics across the life cycle of the building. A decision-making framework is proposed to ensure that the objectives of improved functionality and sustainability are integrated into the design process, Figure 1 illustrates the simple framework by which this design was developed and evaluated. 


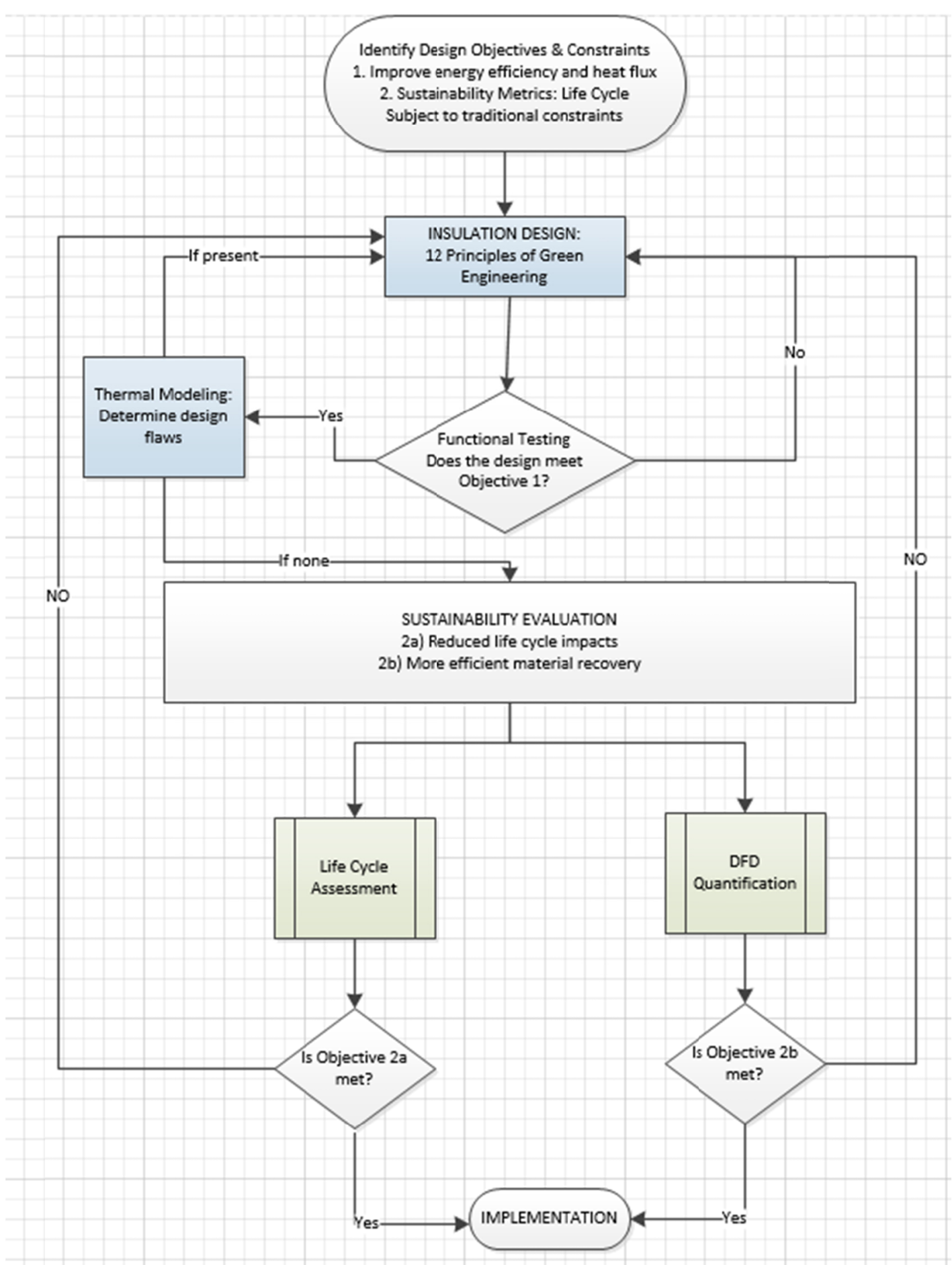

Figure 1. Framework by which the redesigned insulation was developed and tested for both functionality and sustainability

\section{Method}

First, the basic function of the redesigned insulation was tested by monitoring heat flux using experimental methods, as compared to the traditionally insulated wall. A one-dimensional heat flux model was then developed using heat transfer principles derived from Fourier's Law to estimate the heat flux through each insulation medium. Both thermal models: the simple model in Excel, and the thermal analysis developed in ANSYS can be 
used to estimate heat flux through various materials under varying ambient temperatures. The Excel model was intended for a user that needed a quick estimate to determine heat flux across a given insulation. The ANSYS model served a dual purpose: (1) to evaluate heat flux through several points across the surface of the insulation; (2) to identify any key sources of heat loss so that the design could be improved through further modifications.

Secondly, this work utilized life cycle assessment (LCA) to quantify the environmental sustainability of the design decisions associated with replacing the insulation. Employing LCA allowed the investigators to determine if the environmental benefits of material recovery would offset any additional environmental costs associated with the production and use of the alternative insulation. To address another key dimension of sustainability, a disassembly quantification system was developed. This system served to identify inefficiencies in the manufacturing and disassembly process to improve the product's recyclability and enhance material recoverability at the end of its commercial life. For this research, this evaluated cost factor is known as the disassembly cost analysis (DCA).The DCA is then a decision making tool to determine the most efficiently recovered product choice. The method of evaluation entails mapping out the disassembly process of the product and selecting difficulty scores from the database for the tasks involved and logging it on the corresponding spreadsheet. The ideal evaluator has thorough knowledge of the disassembly process, and must assess key aspects of the task performance to assign a difficulty score.

The "Hot-Box" Test Method, as prescribed by ASTM C1636 was utilized for the thermal evaluation. Two hot-boxes were constructed of simple ply wood, measuring $4 \mathrm{ft}$. x $4 \mathrm{ft}$. x 3 inches. Each box was outfitted with 5 Phillips 250-Watt 120-Volt heat lamp bulb that served as the heat source. The control test box (Test Box A) was a $5 \mathrm{ft} x 5 \mathrm{ft}$ structure comprised on polyurethane spray foam insulation (Design A). The alternative design (Test Box B) utilized a honey-comb cartridge; manufactured using vacuum formed recycled plastic obtained from the waste stream of the disassembly and recovery facility to form hexagonal cavities of size 5 " with an outside 90 degree flange, 1 " wide with predrilled holes. The recycled plastic 'honeycomb' mold was used for its ability to provide structural support to the unit (Design B).

Cavities within the honeycomb sheet were subsequently sprayed with heat release adhesive and fitted with 3 in.2 hexagonal plastic packets of industrial grade fume silica beads. Specialized heat resistant silica sand was utilized due to its ability to absorb moisture, prevent conductive and convective heat losses, and regenerate after use. In the production of the silica packets, each plastic packet was subjected to the generation of a vacuum to a level of -40 microns. A reflective heat shield made of recycled polyester fiber encapsulated the cartridge, and a small amount of polyurethane was applied to seal the structure within the walls of the hot box B. An artificial heat source, 4 Philips 250-Watt Incandescent R40 Red Heat Lamp Light Bulbs were utilized as the heat sources in the study.

\section{Results}

\subsection{Assessing Functional Metrics}

Heat flux sensors, Omega- HSF-4 (Stamford, Connecticut) and thermocouples, Omega- Type-T (Stamford, Connecticut) were spaced equidistant apart in a testing chamber to a controlled ambient temperature of $297^{\circ} \mathrm{K}$, relative humidity of $45 \%$ and air pressure of $101 \mathrm{MPa}$. Heat flux were measured over a 24 hour period. The ambient and internal temperature of the hot boxes were monitored for consistency to ensure an accurate test. The facility housing the testing apparatus was a temperature controlled room measuring $12 \mathrm{ft}$. x17ft. pre-fabricated, all metal clad panels with a foamed-in-place urethane core. 


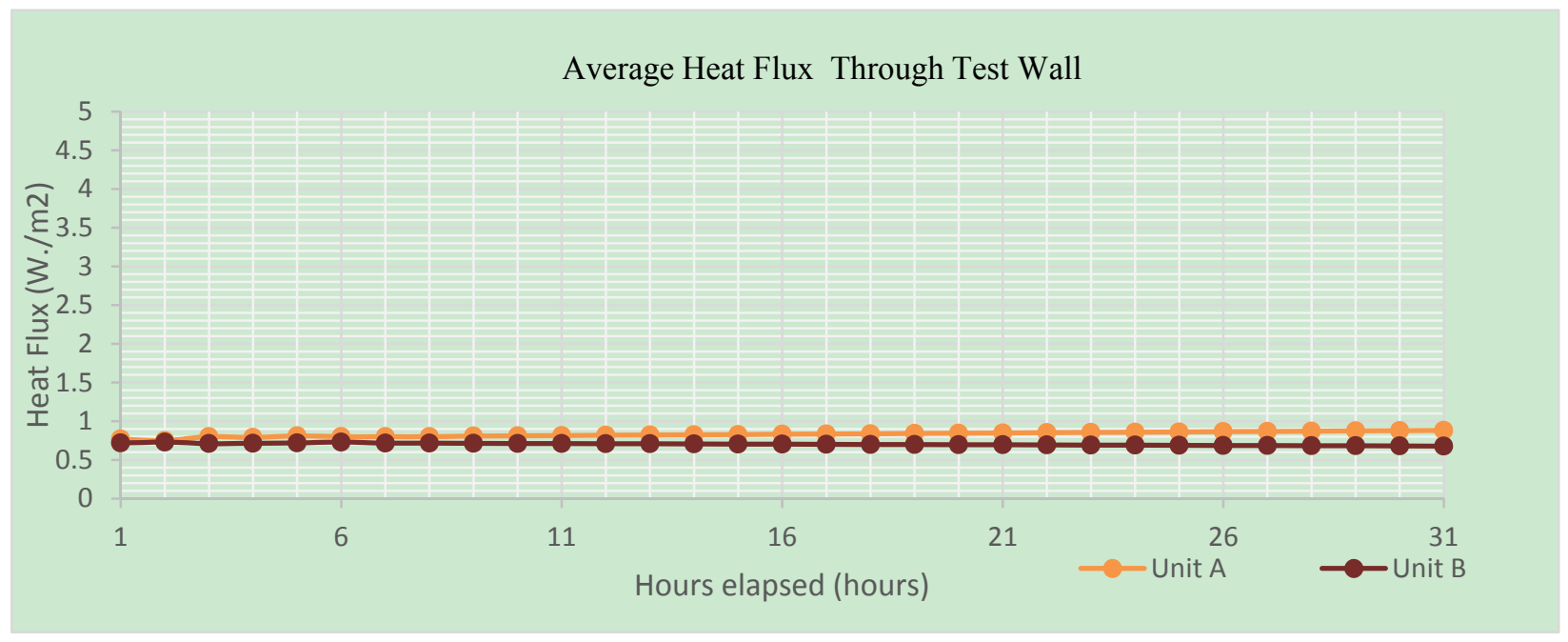

Figure 2. Average heat flux through the wall of Testbox A and Textbox B. Heat flux across the insulation of test-box A was 3-5\% greater than the insulation utilized in Testbox B

The ambient conditions and the internal temperature of the test boxes remained constant during the testing, the fluctuations in heat flux across each type of tested insulation are indicative of the insulation materials and configuration. The ambient temperature remained at $302^{\circ} \mathrm{K}$ with an average deviation of $0.7^{\circ} \mathrm{K}$. When comparing Testbox A to Testbox B, it was observed that there was an average decrease in heat flux of approximately $3-5 \%$, where the insulation varied by unit. Additionally, there was less of a deviation in recorded values of heat flux in Unit B that is characteristic of a more uniform heat resistance configuration. This suggests that the honeycomb structure in conjunction with the primary insulator of vacuumed silica packets was an effective pairing for the purposes of thermal efficiency. As shown, the heat flux remains relatively constant through Unit A and Unit B, and indicates that the heat flux was heavily dependent on the insulation material utilized testing. Once the experimental testing had concluded that the functional metrics had increased energy efficiency and heat flux, a thermal model was employed for further verification. The development of the heat transfer model in ANSYS allowed additional points along the surface of the insulation cover could be analyzed to ensure the satisfaction of the first primary objective of the design: improved functionality.

\subsection{Assessing Environmental Sustainability}

The second part of the research utilized life cycle assessment and "design for disassembly" (DfD) methodologies that included development and application of a comprehensive disassembly quantification system to identify inefficiencies in the separation and recovery processes for each type of insulation. The goal of the life cycle assessment was to determine if the environmental benefits of material recovery would offset any additional environmental costs associated with the production and use of the alternative insulation. The inventory objectives were to (1) Document the resource input, energy use, and emission outputs including products and co-products as it relates to the manufacture and product life time use of a typical building wall of size $100 \mathrm{ft} \times 8 \mathrm{ft}$; and (2) provide a resource to manufacturers and decision makers that would offer opportunities for waste reduction and improved sustainability in the manufacturing process and product design. The life cycle assessment program utilized in this study was SimaPro (Pre Consultants), and impact assessment methodology utilized in this study was EcoIndicator $99(\mathrm{H})$.

The specific manufacturing process utilized for the alternative insulation corresponded to an equally specific disassembly sequence to material recovery with the goal of optimal material recovery. Additional energy for the regeneration and disassembly of Design B was also considered an input to the life cycle assessment. 


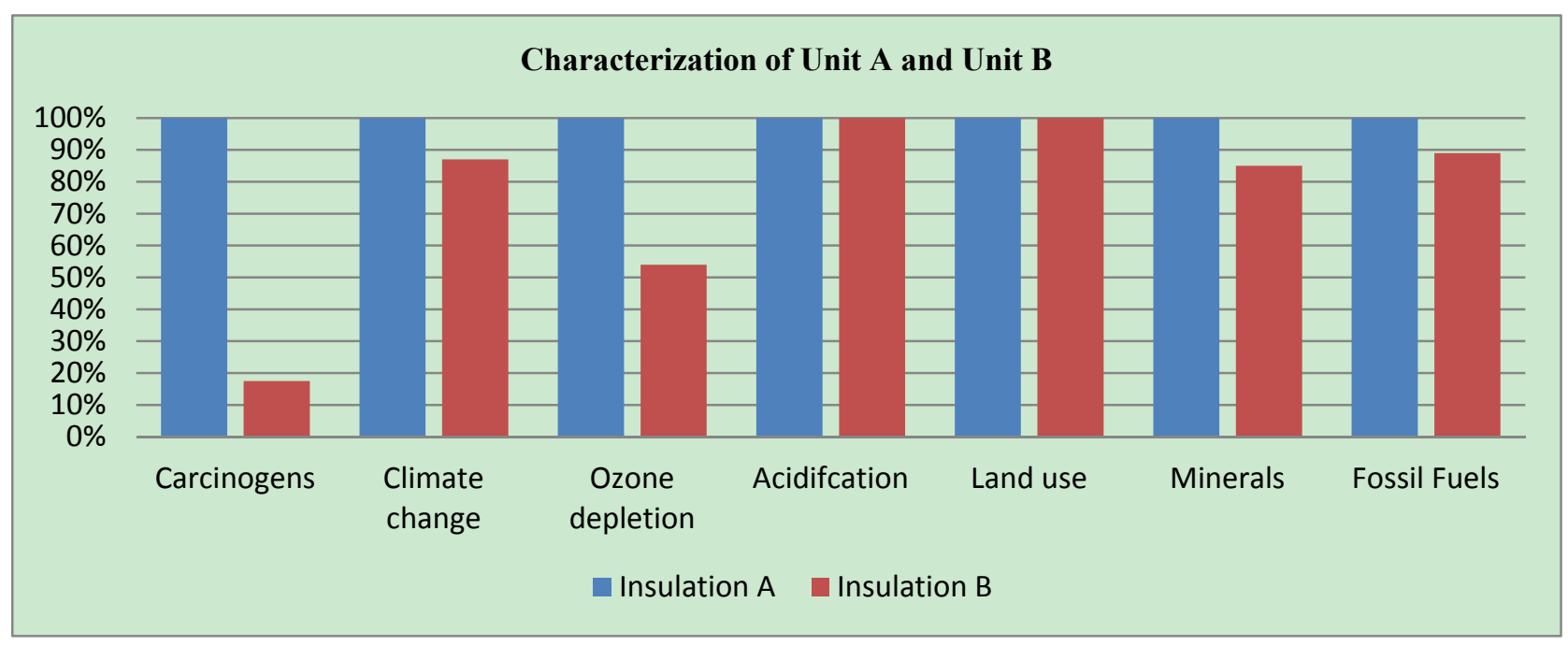

Figure 3. Characterization of Insulation B relative to Insulation A in each key environmental impact category. A decrease in impact in the categories of Climate Change and Carcinogenic Potential are most note-worthy

\section{Discussion}

The assessment revealed the production of both types of insulation was energy intensive, utilizing $35 \%$ of the total energy consumption for Design A, and $29 \%$ of the total energy consumption for Design B. Of particular note, the manufacture of the foam in Design A contributed $65 \%$ of the green-house gases associated with the life cycle of the system. The production of the insulation of Design B was more energy intensive due to the energy associated with the production silica, which contributed significantly. However, a marked decrease in overall energy consumption was observed when an energy analysis was conducted over the life cycle of the unit, where the total points attributed to energy consumption from Design A was 216 and Design B carried a point value of 102. This can be attributed to the high recovery and reuse rate expected by the insulation Design B.

As a secondary evaluation of sustainability, the study also aimed to quantify the efficiency of disassembly and material recovery of the traditionally insulated wall (Design A), compared with the wall employing modified insulation (Design B) This was achieved by employing a disassembly quantification system to determine which insulation type had a higher disassembly efficiency. This study adapted the evaluation method employed by Das et al., (2000). For the purposes of this research, a multi-factor approach to compute an overall 'disassembly factor' (DF) was utilized, allowing an individual to compare scores for competing products. 'DF' is was converted to a cost metric by considering the overhead associated with the processes associated with the disassembly, as well as the labor needed for the execution of separation processes. For this study, this cost factor was known as the disassembly cost analysis (DCA).

The DCA was based on weighted estimates from four different factors: (1) time needed for disassembly (2) effort needed for disassembly (3) ease of access (4) level of hazard to workers. Each factor carried an independent scale that surveyed practitioners utilized to rate each factor. A formula for the design factor (DF) metric incorporated the four factors in an overall weighted scheme. Each factor scale was designed to be simply read and interpreted, so it was as easy to utilize as possible. Each factor was weighted based on the level of importance to overall disassembly efficiency. Two main output metrics from this data were considered and compared to evaluated efficiency and ease of disassembly. Disassembly steps were listed chronologically, and each step was assigned a rating in each of the four factors. The ratings for that particular step in the disassembly process were then summed. This study assumed that: (1) the workforce is trained and familiar with the operation of common types of machinery utilized in the disassembly operations; (2) imperfections or corruption to the fasteners, material or overall unit are minor and will not affect the overall disassembly efficiency.

The disassembly analyses of Design A and Design B revealed an overall cost values of $\$ 1.35$ and $\$ 0.74$ respectively, indicating that when material recovery was considered along with the overall design for disassembly rating, recovering the insulation from the wall A was not economically efficient. Design B had a cost value of $\$ 0.74$ indicating that the value of the recovered material, offset some the costs associated with the disassembly, but was still not cost efficient enough within the given initial overhead needed to mount such a 
disassembly effort. However, the data reveals an opportunity over time for potential profit in the recovery of insulation material utilized in Design B. There is a clear need for a streamlined manufacturing process for both designs, which will allow for maximum recovery efficiency.

\section{Conclusions}

The primary objective of this study was to apply the proposed decision making framework (Figure 1) to explore insulation design measures that would reduce the volume of polyurethane foam utilized in building insulation, while improving or sustaining functional metrics. This was achieved through the development and laboratory testing of an alternative insulation prototype. The framework proposed ensured that the objectives of functionality and sustainability were integrated into the design process. By the process described by the framework, the insulation design was guided and evaluated to satisfy the objectives of improved environmental cost, effectiveness of thermal resistance and efficiency of design for disassembly. To evaluate the success of this approach, the insulation design developed for this research was then compared to the traditional polyurethane foam insulation in two contexts: functionality and environmental sustainability using life cycle assessment, and disassembly efficiency methods. The experimental test conducted in this study showed a decrease in heat flux by an average of $4 \%$, and a savings of 1.2 metric tons of $\mathrm{CO}_{2} \mathrm{e}$ over 20 years per $100 \mathrm{sq}$. ft. of insulation replaced. Experimental and environmental assessment revealed that significant opportunities exist to reduce the overall environmental and heat flux metrics associated with traditional building insulation. Results provide an alternative insulation design for use in construction, and a framework by which to assess the efficiency and environmental performance of sustainable building products.

\section{References}

Allwood, J. M., Laursen, S. E., Rodriguez, C. M., \& Bocken, N. M. P. (2006). Well dressed? The present and future sustainability of clothing and textiles in the United Kingdom. Cambridge: University of Cambridge

Anastas, P. T., \& Zimmerman, J. B. (2003). Design through the 12 principles of green engineering. Environ. Sci. Technology, 37(5), 94A-101A. http://dx.doi.org/10.1021/es032373g

Bjørn, Pe. J. (2011). Traditional, state-of-the-art and future thermal building insulation materials and solutions Properties, requirements and possibilities. Energy and Buildings, 43(10), 2549-2563. http://dx.doi.org/10.1016/j.enbuild.2011.05.015

Dillard, J., Brown, D., \& Marshall, R. S. (2005). An environmentally enlightened accounting. Accounting Forum, 29(1), 77-101. http://dx.doi.org/10.1016/j.accfor.2004.12.001

EPA. (2011). Protection of the Stratospheric Ozone: Supplemental Rule Regarding a Recycling Standard Under Section 608 of the Clean Air Act (2003) EPA, Washington DC. Retrieved from http://www.gpo.gov/fdsys/pkg/FR-2003-07-24/pdf/03-18150.pdf

Lei, S., Donghui, Z., Jingzhu, S., Yourun., \& Yi, Q. (2001). A Generalized Framework and Methodology for Product Planning in Eco-Industrial Parks. International Conference on Cleaner Production. Beijing, China. 2001.

Little, J. C., Hester, E. T., \& Carey, C. (2016) Assessing and Enhancing Environmental Sustainability: A $\begin{array}{lllll}\text { Conceptual Review. Environ. Sci. Technology, 50(13), 6830-6845. } & \end{array}$ http://dx.doi.org/10.1021/acs.est.6b00298

Mulvihill, M. J., Beach, E. S., Zimmerman, J. B., \& Anastas, P. T. (2011). Green Chemistry and Green Engineering: A Framework for Sustainable Technology Development. Annual Review of Environment and Resources, 36, 271-293. http://dx.doi.org/10.1146/annurev-environ-032009-095500

Zimmerman, J. B., \& Anastas. (2005). Approaches to Innovations in the Aerospace Sector through Green Engineering and Green Chemistry, SAE Transactions. Journal of Aerospace, 114(1), 987-993.

\section{Copyrights}

Copyright for this article is retained by the author(s), with first publication rights granted to the journal.

This is an open-access article distributed under the terms and conditions of the Creative Commons Attribution license (http://creativecommons.org/licenses/by/4.0/). 